\title{
A história do lúdico na educação
}

\author{
The history of playful in education
}

\author{
Alexandre Sant'Anna \\ Universidade Cruzeiro do Sul - SP \\ santannalex@ig.com.br \\ Paulo Roberto do Nascimento \\ Universidade Cruzeiro do Sul - SP \\ paulo.nascimento@ cruzeirodosul.br
}

\begin{abstract}
Resumo
Este artigo tem como objetivo contribuir para o enriquecimento profissional dos professores que ensinam matemática na perspectiva de um conhecimento mais aprofundado sobre a história do uso do lúdico no processo de ensino e aprendizagem, resgatando sua utilidade desde os primórdios, passando pela Idade Média até os dias atuais. A importância do lúdico como instrumento metodológico é abordada sob a ótica da utilização dos mesmos na busca de um melhor aprendizado dos alunos, em relação aos conhecimentos matemáticos, partindo da escolha da melhor atividade lúdica a ser utilizada para cada conteúdo programático, dos objetivos a serem alcançados com o uso dessas atividades, que favoreçam a exploração do potencial e o desenvolvimento das habilidades que eles proporcionam. Diversos autores defendem a utilização do lúdico em sala de aula como um instrumento metodológico para o ensino da matemática. Propomos neste artigo que os professores devam ter formação para que possam utilizar tal instrumento da melhor forma possível na busca do alcance dos objetivos traçados.
\end{abstract}

Palavras-chave: Aprendizagem Significativa. Formação. Lúdico.

\begin{abstract}
This article aims to contribute to the professional enrichment of teachers who teach mathematics from the prospect of a deeper knowledge about the history of the use of playful in teaching and learning, rescuing its usefulness from the very beginning through the Middle Ages until present days. The importance of playful as a methodological tool is discussed from the viewpoint of resource used in searching for an improvement of students learning, this related to mathematical knowledge, based on the best activity playful to be used content programmatic, on the objectives to be achieved with the use of these activities, to encourage the exploration and potential development of skills that they provide. Several authors advocate the use of playful in the classroom as a methodological tool for the teaching of mathematics. We propose in this paper that teachers should have formation so they can use such an instrument in pursuit of achieving the planned goals.
\end{abstract}

Keywords: Meaningful Learning. Training. Playful. 


\title{
Introdução
}

A palavra lúdico se origina do latim ludus que significa brincar. Corbalán menciona o que entendemos ser uma excelente contribuição para que possamos expressar nossa concepção do lúdico e de seu uso como instrumento metodológico na formação dos professores para que mude sua prática nas aulas de matemática:

\begin{abstract}
Ensinar e aprender matemática pode e deve ser uma experiência com bom êxito do sentido de algo que traz felicidade aos alunos. Curiosamente quase nunca se cita a felicidade dentro dos objetivos a serem alcançados no processo ensino-aprendizagem, é evidente que só poderemos falar de um trabalho docente bem feito quando todos alcançarmos um grau de felicidade satisfatório. (CORBALÁN, apud ALSINA, 1994, p. 14).
\end{abstract}

O lúdico é a brincadeira, é o jogo, é a diversão e é sob esse ponto de vista que desenvolvemos essa pesquisa, para que o aprendizado de matemática se torne mais atrativo e divertido. $\mathrm{O}$ brincar esteve presente em todas as épocas da humanidade, mantendo-se até os dias atuais. Em cada época, conforme o contexto histórico vivido pelos povos e conforme o pensamento estabelecido para tal, sempre foi algo natural, vivido por todos e também utilizado como um instrumento com um caráter educativo para o desenvolvimento do individuo.

Na história antiga há relatos de que o ato de brincar era desenvolvido por toda a família, até quando os pais ensinavam os ofícios para seus filhos. Destacamos que para cada época e sociedade a concepção sobre educação sempre teve um entendimento diferenciado, logo o uso do lúdico seguiu tal concepção. Os povos primitivos davam à educação física uma importância muito grande e davam total liberdade para as crianças aproveitarem o exercício dos jogos naturais, possibilitando assim que esses pudessem influenciar positivamente a educação de suas crianças.

Platão ${ }^{1}$, já em meados de 367 a.C., apontou a importância da utilização dos jogos para que o aprendizado das crianças pudesse ser desenvolvido. Afirmava que em seus primeiros anos de vida os meninos e meninas deveriam praticar juntos, atividades educativas através dos jogos.

Rabelais $^{2}$, no século XV, já proclamava que o ensinamento deveria ser através dos jogos, dizendo a todos que deveriam ensinar às crianças o gosto pela leitura, pelo desenho, pelos jogos de cartas e fichas que serviam para ensinar a aritmética e até mesmo a geometria.

\footnotetext{
${ }^{1}$ Nome verdadeiro - Arístocles; viveu entre 427 AC e 347 AC; filósofo grego; chamado de Platão por causa do seu vigor físico e ombros largos (platos significa largueza).

${ }^{2}$ François Rabelais viveu entre 1484 e 1553 ; escritor renascentista francês.
} 
Outros teóricos também contribuíram para que o lúdico pudesse ser utilizado na educação dentro do processo de ensino e aprendizagem. Destacamos: Rousseau ${ }^{3}$ e Pestalozzi ${ }^{4}$, no

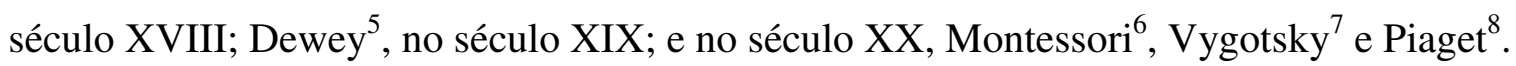

Segundo as teorias de Vygotsky o ser humano se desenvolve a partir do aprendizado, que envolve a interferência direta ou indireta de outros seres humanos, sendo que a mediação faz a diferença, interferindo na relação de aprendizagem da criança e fazendo com que as funções psicológicas superiores se desenvolvam no ser humano. Cita que o jogo é um instrumento importante para esse desenvolvimento, sendo que os jogos e suas regras criam nos alunos uma zona de desenvolvimento proximal (ZDP), proporcionando desafios e estímulos para a busca de conquistas mais avançadas, ensinando também a separar objetos e significados.

Vygotsky explica que a zona de desenvolvimento proximal (ZDP) é o percurso que o ser humano faz até chegar a um nível de amadurecimento real, sendo chamado por ele de zona de desenvolvimento real (ZDR) que é a capacidade do ser humano realizar tarefas independentes. Ao utilizar o lúdico para o ensino da matemática o professor está mediando o aprendizado dos alunos que, a partir da ZDP pode efetivamente adquirir um conhecimento, proporcionando alterações em sua estrutura cognitiva.

Piaget atribui ao jogo um papel essencial para o desenvolvimento infantil; acredita que ao jogar as crianças assimilam e transformam a realidade. Propõe uma subdivisão dos jogos, por faixa etária, sendo elas:

- Primeira etapa - para crianças de zero a dois anos de idade que ele chama de período sensório-motor, as crianças repetem situações simplesmente por prazer;

- Segunda etapa - para crianças de dois a sete anos que ele chama de período préoperatório em que as crianças não fazem o exercício mental, mas sim a representação do ocorrido;

\footnotetext{
${ }^{3}$ Jean-Jacques Rousseau viveu entre 1712 e 1778; filósofo, teórico político e escritor suíço.

${ }^{4}$ Johann Heinrich Pestalozzi, viveu entre 1746 e 1827 na Suíça; conhecido como "O Educador da Humanidade".

${ }^{5}$ John Dewey viveu entre1859 e1952 nos E.U.A; filósofo e psicólogo; sua obra pedagógica "Democracia e Educação" (1916) foi determinante para a evolução do sistema educativo norte-americano.

${ }^{6}$ Maria Montessori viveu entre $\underline{1870}$ e $1 \underline{952}$ na Itália; educadora, médica e feminista; criou o método montessori de aprendizagem,

${ }^{7}$ Lev Semenovitch Vygotsky viveu entre 1896 e 1934 na Russia; psicólogo; algumas obras publicadas no Brasil: Formação Social da Mente, Psicologia da Arte, Pensamento e linguagem, Psicologia Pedagógica, Linguagem, desenvolvimento e aprendizagem.

${ }^{8}$ Jean William Fritz Piaget viveu entre 1896 e 1980 na Suíça; foi um epistemólogo suíço, considerado o maior expoente do estudo do desenvolvimento cognitivo; com dezenas de publicações em português citamos uma obra em especial: Aprendizagem e Conhecimento de 1979.
} 
- Terceira etapa - para crianças acima dos sete anos, que ele chama de período operatório em que os jogos são de regras. É a união dos outros dois jogos, explorando, neste caso, a coletividade para o ato de jogar, sendo importante a cooperação entre as crianças.

A utilização do lúdico na educação tem também, além do objetivo de desenvolver o aprendizado de forma mais atrativa para o aluno, o objetivo do resgate histórico-cultural dessas atividades. É um ótimo momento para o reconhecimento do seu histórico familiar e de sua cultura regional.

Adquirimos desde criança as mais diferentes formas de conhecimento: seja popular, cientifico, cultural, religioso, aprendendo-as de maneiras e objetivos diferentes, mas com algo comum para todos os seres: o mundo da criança, independente de suas origens, é lúdico e ilusório e o mundo do adulto se abstém de ludicidade, sendo realista.

O ensino da matemática deve ser desenvolvido de forma que o aprendizado seja significativo, com metodologias que estejam ligadas a vivencia dos alunos.

Ausubel cita em uma de suas obras que:

A aquisição e a retenção de conhecimentos são atividades profundas e de toda uma vida, essenciais para o desempenho competente, a gestão eficiente e o melhoramento das tarefas cotidianas. (AUSUBEL, 2000).

Ressaltamos que a aprendizagem significativa foi utilizada para o aprendizado dos povos passados dentro das suas reais necessidades e buscando alcançar os objetivos da sociedade moderna. Avançaremos, neste sentido, com práticas já existentes, com o objetivo de contribuir para a melhora do ensino da matemática.

Os modelos de ensino trazem a mesma espinha dorsal desde os primórdios até os dias atuais. Mudanças sistemáticas aconteceram justamente na forma como se desenvolve esse ensino, mas com a perda das maneiras suaves, alegres, felizes, objetivas, que uma criança mereça aprender.

$\mathrm{Na}$ Grécia antiga era através dos jogos que se passava ensinamento às crianças. Os índios ensinavam e ensinam seus costumes através da ludicidade. No Brasil da Idade Média, os jesuítas ensinavam utilizando brincadeiras como instrumentos para a aprendizagem. Desde os primórdios, a metodologia lúdica sempre foi valorizada pelos povos, sejam quais forem, e a inquietação torna-se justamente a de: será que nos dias atuais esse instrumento, já ratificado 
por diversos autores de renome, está sendo valorizado no ensino, principalmente no ensino da matemática?

Trazemos como bases de conhecimento todo um conjunto adquirido desde os primórdios e devemos valorizá-los e aplicá-los no ensino. A utilização da ludicidade como instrumento metodológico para o ensino de nossas crianças é um desses ensinamentos que não devemos deixar para trás. Devemos fazer o mesmo com a maneira que ensinamos nossas crianças, que estas tenham o aprendizado matemático de maneira espontânea, onde possam ser ativas durante o processo de aprendizagem e que este se torne significativo.

Kishimoto em suas obras contribui com o seguinte relato:

A criança é um ser em pleno processo de apropriação da cultura, precisando participar dos jogos de uma forma espontânea e criativa. (KISHIMOTO, 2000).

Precisamos nos apropriar do conhecimento sobre como utilizar o lúdico como instrumento metodológico para o ensino. Este deve contribuir para que nossos alunos tenham um aprendizado qualitativo e significativo.

\section{A história do lúdico no Brasil}

Os índios, os portugueses e os negros foram os precursores dos atuais modelos e maneiras de desenvolvimento do lúdico que mantemos até hoje, no Brasil. Nos últimos séculos, houve no Brasil, uma grande mistura de povos e raças, cada qual com suas culturas, crenças, educação. Umas diferentes das outras e também com sua forma de desenvolvimento da ludicidade entre seus pares; todavia essa herança torna nosso país ainda mais rico do ponto de vista cultural e educacional.

Toda herança cultural e educacional deve ser utilizada para o aprendizado universal de nossos alunos, haja vista que lidamos com várias etnias, raças e povos e, portanto, devemos resgatar e desenvolver o que de mais importante houver de cada uma para o ensino dos alunos nos dias atuais.

Os jogos e brincadeiras que temos hoje são originários dessa miscigenação que ocorreu nesse período, mas é incerto afirmar de qual povo exatamente seriam suas origens. O que devemos ressaltar é justamente que, o que temos é um material importante trazido como herança dos nossos antepassados e que devem ser preservados, valorizados e utilizados para o ensino dos nossos alunos, sempre estimulando o resgate histórico que merece cada um deles. 
Os índios sempre se fizeram valer de seus costumes para ensinar seus filhos a caçar, pescar, brincar, dançar; uma maneira lúdica do aprendizado e que representa a cultura, a educação e a tradição de seus povos. Seus filhos constroem seus próprios brinquedos com materiais extraídos da natureza; caçam e pescam com o olhar diferente dos adultos e seus objetivos são sempre o de brincar e se divertir sem que de fato o façam para sua real necessidade de sobrevivência.

Os negros também trouxeram seus costumes, semelhante aos dos índios, sendo necessária, desde criança, a construção de seus próprios brinquedos, saber pescar, nadar, caçar. Cultura, educação e tradição desenvolvidas de forma criativa, lúdica, e que ao mesmo tempo satisfazia suas reais necessidades de sobrevivência.

Os filhos dos portugueses quando vieram para o Brasil não tinham seus contatos com a ludicidade como atos para a sobrevivência, o tinham como ato de lazer e para seu enriquecimento intelectual. Seus costumes, trazidos de Portugal, eram totalmente diferentes dos existentes no Brasil dos índios e dos trazidos pelos negros, em suas bagagens, nos navios negreiros da África até aqui.

Já no final da Idade Média e inicio da Idade Moderna em meados do século XV a Igreja Católica, tornou-se responsável por extinguir os jogos da educação por considerar o jogo algo profano. Seu uso para o ensino volta a ter destaque logo em seguida com os jesuítas ${ }^{9}$, mas que não se perpetuou, pois em meados de 1758 os jesuítas foram expulsos e o Brasil ficou sem nenhum sistema organizado de ensino. Hora ou outra vinham professores enviados de Portugal para ministrar cursos, tais como o curso de álgebra, segundo uma carta régia de 1799, sobre o ensino de matemática no Brasil.

Citando o século XX, tivemos algumas propostas novas, como a Pedagogia Nova, ajudando a estruturar um novo olhar para o ensino, além do Positivismo e o Tecnicismo do Ensino de Ciências. Nas primeiras décadas do século XX, o aprender fazendo, a pesquisa investigatória, o método da redescoberta, os métodos de solução de problemas como também as feiras e clubes de ciências foram as grandes mudanças ocorridas para um ensino que até então não tinha essa preocupação.

A Revolução de 1930 que pôs fim à Primeira Republica, se tornou um dos movimentos mais importantes no Brasil, e também para a educação brasileira. Todos valorizavam o papel que a

\footnotetext{
${ }^{9}$ Padres da Igreja Católica pertencentes à Companhia de Jesus, fundada em 1534 por Inácio de Loiola com o intutito de barrar o avanço do protestantismo no mundo.
} 
educação deveria cumprir para sua realização, coerentemente com o seu horizonte ideológico. Foi então criado o Ministério da Educação e Saúde Pública, tendo Francisco Campos, o primeiro Ministro da Educação.

Esse olhar para a educação surgiu a partir da necessidade do sistema econômico, pois a Revolução de 30 ficou marcada pela abertura do Brasil para o mundo capitalista de produção, e o Brasil, por ter acumulado muito capital até então, passou a investir no mercado interno e na produção industrial. A partir daí temos uma nova realidade que era a necessidade de mão de obra especializada e para tal era preciso investir na educação.

Em 1932 foi lançado por um grupo de educadores, o Manifesto dos Pioneiros da Educação Nova, dirigido ao povo e ao governo, o documento apresentava a diversidade teórica e ideológica do grupo que o concebeu, mas com ideias consensuais. Destacamos a proposta de um programa de reconstrução educacional em âmbito nacional e o princípio da escola pública, leiga, obrigatória, gratuita e do ensino comum para ambos os sexos, que deu resultados num curto espaço de tempo, pois já na promulgação da nova Constituição em 1934, a educação passa a ser direito de todos, devendo ser ministrada pela família e pelos Poderes Públicos. Após a reforma o currículo do ensino secundário passou a ser seriado, com a disciplina de matemática reunindo a aritmética e a geometria.

Da década de 30 até a década de 50, quase não houve alterações no ensino da matemática. Somente em 1955, com a realização do I Congresso Brasileiro de Ensino da Matemática em Salvador, é que foi reconhecido que o currículo secundário precisava ser atualizado, com o propósito de ser mais entrosado com o conteúdo do ensino universitário. Pelo mundo afora ocorria o mesmo movimento, mas com outros interesses.

A França reconhecia o sucesso da reorganização de todo conhecimento matemático numa apresentação axiomática e dedutiva da teoria dos conjuntos que Bourbaki ${ }^{10}$ realizou. A partir daí diversos educadores também propuseram a mesma organização no domínio da matemática elementar, colocando-a como elo entre a matemática secundária e superior. Temos com o casamento desses dois movimentos em torno do ensino da matemática, o nascimento da chamada Matemática Moderna que se tornou mundial num curto espaço de tempo.

A Matemática Moderna trazia como proposta a eliminação do ensino da matemática baseado na memorização de regras e no treino de algoritmos, introduzindo a teoria dos conjuntos na

\footnotetext{
${ }^{10}$ Pseudônimo coletivo, sob o qual um grupo de matemáticos, majoritariamente franceses, escreveram uma série de livros que expunham a matemática avançada moderna, editados a partir de 1935.
} 
tentativa de unificar a linguagem dos vários ramos da matemática, mas mantendo o foco nos procedimentos e isolando a geometria.

No Brasil vários grupos de estudos foram constituídos para estudar a matemática moderna. Citamos alguns que foram criados à época: o Grupo de Estudos Ensino da Matemática (GEEM, São Paulo), o Grupo de Estudos Matemática de Porto Alegre (GEMPA, Porto Alegre) e Grupo de Estudos e Pesquisas de Matemática (GEPEM, Rio de Janeiro).

O Ministério da Educação e Cultura, nome atribuído a partir de 1953, quando foi criado o Ministério da Saúde (desmembrando a estrutura até então do ministério da educação e da saúde publica), apoiou discretamente as mudanças provocadas pela matemática moderna. Somente em meados dos anos 70 é que temos a criação de um movimento chamado de Movimento de Educação Matemática, com grupos de matemáticos e especialistas, organizados para estudos e pesquisas.

Todos esses especialistas tinham o mesmo pensamento de que o ensino de matemática, como vinha sendo realizado, estava ultrapassado. Passaram a estudar a psicologia de desenvolvimento do conhecimento da criança, além de como fazer para avaliá-las de maneira diferente da até então aplicada pelos professores, levando em consideração para o ensino da matemática, a realidade vivida pelos alunos e que esta influía na sua aprendizagem.

À época foram publicadas várias técnicas e métodos para o ensino da matemática, de acordo com pesquisas e estudos realizados por matemáticos e especialistas desse movimento, os quais defendiam que a resolução de problemas, ao contrário do mecanicismo, ajudava os alunos a compreenderem os conteúdos matemáticos, devendo então ser aplicados antes dos conteúdos.

Defendiam a utilização da modelagem para o ensino da matemática, ou seja, que ao invés do professor partir das teorias matemáticas para o ensino, que a realidade dos alunos fosse levada para dentro da escola, dentro da sala de aula e que as situações vividas pelos alunos fossem utilizadas como exemplos para o desenvolvimento da aprendizagem matemática.

Defendiam que a história da matemática fizesse parte dos conteúdos a serem desenvolvidos com os alunos, com o intuito de compreenderem toda a evolução matemática e por que aprendê-la naquele momento de sua vida.

Foi feito um movimento importante e fundamental para que os professores ao ensinar matemática levassem em consideração as experiências vividas pelos alunos no contato com a matemática, no seu cotidiano, pois de alguma forma esses alunos já tiveram contato como a 
matemática, digamos popular, não teórica - cientifica, mas fundamental para torná-la significativa para esses alunos, chamado de abordagem etnomatemática.

Ubiratan D’Ambrósio, conhecido como um dos maiores defensores da etnomatemática cita que:

Quando o aluno chega na escola ele traz experiências de casa, traz o conhecimento de jogos, de brincadeiras, pois já viveu sete anos produtivos e criativos. Aprendeu a falar, andar, brincar. Isso não é aproveitado pelo sistema escolar. O professor parece que pede: 'esqueça tudo que você fez e aprenda números e coisas mais intelectualizadas'. (D'AMBRÓSIO apud HUBNER et al., 2003).

D’Ambrósio, cita ainda a valorização demasiada por parte dos professores, do ensino formal, sem que possam se desprender dele para um aprofundamento maior na etnomatemática. Segundo ele:

\begin{abstract}
É mais importante aquilo que a criança pode fazer com um instrumento que trouxe de sua vida anterior à escola do que dar instrumentos novos. Com o que ela já sabe de casa pode fazer muito e ser feliz. Só quando o aluno sentir que necessita de algo novo é que o educador deve intervir cultivando e explorando esse desejo de saber e fazer mais. Neste momento, o professor pode dizer: 'você parou aí, vou mostrar como ir adiante'. Aos poucos, a criança irá aprender as coisas novas apresentadas. A matemática é isso. Só que esse momento não está sendo adequadamente explorado pelo sistema educacional. Falta uma pedagogia na linha da etnomatemática. (D'AMBRÓSIO apud HUBNER et al., 2003).
\end{abstract}

Inclui-se na defesa do movimento de educação matemática a utilização dos computadores, mesmo que a título precário, mas que pudesse ser pensado, pois na época esse instrumento não era tão acessível como nos dias atuais, mas servia como instrumento para o ensino da matemática, principalmente para a utilização de jogos na relação de ensino e aprendizagem matemática.

Silvia Batista fundamenta tais defesas quando cita que:

Pensar a educação na sociedade da informação exige considerar um leque de aspectos relativos às tecnologias de informação e comunicação, a começar pelo papel que elas desempenham na construção de uma sociedade que tenha a inclusão e a justiça social como uma das prioridades principais. (TAKAHASHI apud BATISTA, 2004). 
Vemos que se tornou um movimento audacioso e que propunha uma verdadeira revolução no ensino da matemática, até então tradicional e mecanicista, e que atendia aos reais interesses políticos esperados que a educação proporcionasse - não aos interesses educacionais dos profissionais que discutiam a educação como mecanismo de desenvolvimento do indivíduo e que implicitamente esta se tornasse de fato transformadora social.

Com a Agenda para Ação, documento que foi produzido nos anos 80 pelo National Council of Teachers of Mathematics — NCTM —, dos Estados Unidos, novas propostas para a melhoria do ensino de matemática foram trazidas para a discussão, propostas como a utilização de resolução de problemas como mecanismo de aprendizagem significativa. Dentre as propostas como as defendidas, na década de 70, pelo movimento da educação matemática, citamos a de que: ao se ensinar matemática, alguns aspectos deveriam ter total relevância para que de fato o aprendizado ocorresse. Aspectos como os sociais, cognitivos, antropológicos e linguísticos, algo que até então não havia sido discutido dentro do processo de construção das propostas educacionais.

No final do século XX, já nos últimos anos, temos um avanço significativo no Brasil, com a publicação dos PCNs, os Parâmetros Curriculares Nacionais, propondo quais objetivos deveriam ser alcançados ao final de cada ciclo em que o aluno estudasse, proposta de quais conteúdos deveriam ser desenvolvidos, mecanismos de avaliação, orientações didáticas, para os professores.

Um material muito bem elaborado e disponibilizado pelo Ministério de Educação. A proposta do ensino da matemática foi elaborada por profissionais do Movimento de Educação Matemática, com objetivos totalmente diferentes dos propostos em documentos anteriores, conforme traz o próprio PCN da área de matemática:

(...) Visam à construção de um referencial que oriente a prática escolar de forma a contribuir para que toda criança e jovem brasileiros tenham acesso a um conhecimento matemático que lhes possibilite de fato sua inserção, como cidadãos, no mundo do trabalho, das relações sociais e da cultura. (PCNs, 1997).

Propondo também que:

(...) A Matemática é componente importante na construção da cidadania, na medida em que a sociedade utiliza, cada vez mais, de conhecimentos científicos e recursos tecnológicos, dos quais os cidadãos devem se apropriar. A aprendizagem em Matemática está ligada à compreensão, isto é, à apreensão do significado; aprender o significado de um objeto ou acontecimento pressupõe vê-lo em suas relações com outros objetos e acontecimentos. Recursos didáticos como jogos, livros, vídeos, 
calculadora, computadores e outros materiais têm um papel importante no processo de ensino aprendizagem. Contudo, eles precisam estar integrados a situações que levem ao exercício da análise e da reflexão, em última instância, a base da atividade matemática. (PCNs, 1997).

Contudo diante de todas as contribuições históricas, cada qual em sua época, e para a busca de atingir um melhor ensino da matemática, acreditamos que as ultimas décadas do século XX, foram as que do ponto de vista social trouxeram avanços significativos esse ensino.

O uso do lúdico no ensino da matemática embora tão utilizado em todas as épocas, perpassando por vários sistemas, ficou fortalecido com os estudos e pesquisas das áreas das ciências humanas que tratam do desenvolvimento cognitivo da criança. Temos a Psicologia, a Pedagogia e até mesmo a Sociologia estudando como o convívio social das crianças influencia no seu aprendizado, dando ênfase à utilização do lúdico como objeto de estudo e pesquisa para o desenvolvimento da criança.

Passamos então a ter estudos publicados que tratam da educação lúdica não somente como um ato simplista de brincar, sem qualquer relação com o desenvolvimento do ser humano, sendo considerado em qualquer fase da vida, um instrumento relacional com o conhecimento. Podendo esta, ser desenvolvida como uma ação isolada ou coletiva e até mesmo indireta com o ato de conhecimento. Desenvolvendo um pensamento crítico, reflexivo e ativo no ser humano, enriquecendo seu senso de responsabilidade e cooperativismo, proporcionando a este uma apropriação das funções cognitivas e sociais para seu desenvolvimento.

Com o Movimento de Educação Matemática nas últimas décadas do século XX e as teorias das Ciências Humanas para o ensino e aprendizagem, o uso do lúdico para o ensino da matemática se tornou mais valorizado como instrumento metodológico. Com ênfase total a partir de sua inserção nos Parâmetros Curriculares Nacionais em 1997, publicação que passou a nortear o atual modelo de ensino no Brasil.

A formação dos professores deve acompanhar tais mudanças estruturais do ensino da matemática estreitando a relação entre as teorias que propõem tais mudanças com a prática docente. Desde a época da matemática moderna, faltam investimentos para a formação do professor dificultando assim os avanços necessários para tal estreitamento. Há um distanciamento entre o ensino proposto pelos PCN e o praticado em sala de aula, o que torna essa prática sem rumo quanto aos seus parâmetros.

O uso da etnomatemática, da modelagem matemática, da resolução de problemas relacionais, o lúdico matemático, a tecnologia como instrumento, precisa ser algo comum da prática 
docente. Uma política efetiva de formação para os professores possibilita a estes uma imersão nos métodos e técnicas de ensino e estes possibilitam um aprendizado matemático significativo.

Este aprendizado deve contribuir para tornar o aluno um sujeito crítico, intelectual, voraz para a busca de uma sociedade justa, onde seus conhecimentos advindos do seu processo de desenvolvimento educacional possam de fato inseri-lo na sociedade como um ator principal de transformações.

Pensadores como Piaget, Wallon, Dewey, Leif, Vygotsky, defendem que o uso do lúdico é essencial para a prática educacional, no sentido da busca do desenvolvimento cognitivo, intelectual e social dos alunos. Considerando que os jogos estão presentes nas vidas, não só da criança, mas também dos adultos, isto os torna instrumentos que podem ser utilizados para o desenvolvimento de qualquer pessoa e, portanto, deve ser levado em consideração pelos educadores em qualquer nível de ensino.

Qualquer atividade lúdica provoca estímulos nas pessoas, explorando seus sentidos vitais, operatórios e psicomotores, propiciando o desenvolvimento completo das suas funções cognitivas.

Kishimoto alerta que:

(...) Se quisermos aproveitar o potencial do jogo como recurso para o desenvolvimento infantil, não poderemos contrariar sua natureza, que requer a busca do prazer, a alegria, a exploração livre e o não-constrangimento. (Kishimoto, 1995) .

Macedo, Petty e Passos defendem que:

O brincar é agradável por si mesmo, aqui e agora. Na perspectiva da criança, brinca-se pelo prazer de brincar, e não porque suas consequências sejam eventualmente positivas ou preparadoras de alguma outra coisa. (MACEDO, PETTY \& PASSOS, 2005).

O professor tem um papel fundamental a partir de então para que explore as atividades lúdicas, com o objetivo de que seus alunos possam ter um aprendizado matemático significativo, sem que tais atividades percam as suas essências, mas que resultem no objetivo esperado.

D’Ambrósio (1993), sugere que o professor de matemática, para as perspectivas atuais, deva ter visão da matemática como disciplina investigativa e inserida no cotidiano; visão da atividade matemática como investigativa; visão da aprendizagem matemática como 
propiciadora do desenvolvimento cognitivo do aluno; além de enxergar o que deve ser um ambiente propício ao aprendizado do aluno, com perspectiva de estimulo de atitudes críticas, por parte do aluno, com relação ao conhecimento matemático.

\section{Conclusões}

A utilização do lúdico no ensino da matemática deve ser explorado no sentido do prazer, do novo, ativo, pensante, questionador e reflexivo no processo de aprendizagem. Para tanto é fundamental que o professor conheça a atividade lúdica escolhida. Que tenha pleno conhecimento dessa atividade, para fazer com que os alunos ultrapassem a barreira da simples tentativa, do erro, ou de jogar ou brincar pela simples diversão.

O professor deve escolher uma metodologia de trabalho que permita a exploração do potencial da atividade lúdica no desenvolvimento das habilidades. Se o material não for potencialmente significativo, os alunos, mesmo com grande disposição para incorporar o conteúdo proposto, à sua estrutura cognitiva, terão aprendizagem mecanizada, sem significado efetivo para seu conhecimento.

Ausubel define que:

As tarefas de aprendizagem por memorização, como é óbvio, não se levam a cabo num vácuo cognitivo. Pode relacionar-se com a estrutura cognitiva, mas apenas de uma forma arbitrária e literal que não resulta na aquisição de novos significados. (AUSUBEL, 2000).

O ensino da matemática pode e deve ser realizado dentro de um espaço escolar propositivo, no sentido da diversão e, sério quando esta diversão está intimamente ligada aos objetivos a serem alcançados no processo de ensino e de aprendizagem. A produção passa a ser um componente de esforço e de desafio automático, possibilitando a construção e re-elaboração do conhecimento por parte dos alunos.

É fundamental que o professor tenha pleno domínio do que está propondo e, para isso, a sua formação deve proporcionar que seus conhecimentos sejam explorados através do uso do lúdico, assim como a familiarização com tal instrumento. Para que a aprendizagem seja realmente significativa, Ausubel, afirma que o conteúdo adquirido tem que estar claro, preciso, e deve haver competência em transferi-lo a situações novas, diferentes daquelas que foram usadas para o seu ensino. 
O professor ao conseguir definir conceitos, discorrer sobre eles ou mesmo resolver problemas complexos, precisa fazer com que tudo isso se transforme ao propor o mesmo processo aos seus alunos, de que a aprendizagem seja realmente significativa.

Ausubel argumenta que:

(...) uma longa experiência em fazer exames faz com que os alunos se habituem em memorizar não só proposições e fórmulas, mas também causas, exemplos, explicações e maneiras de resolver 'problemas típicos. (AUSUBEL apud MOREIRA, 1999).

Ao propor, por exemplo, uma atividade lúdica para seus alunos, o professor deve efetivamente ter conhecimento dos objetivos a serem alcançados, bem como verificar a adequação metodológica que deseja utilizar à faixa etária com que trabalha, podendo, se isso não ocorrer, o jogo tornar-se uma brincadeira sem objetivos e que os alunos memorizem seus procedimentos sem que haja uma aprendizagem significativa.

O ensino deve iniciar-se sempre a partir do que o aluno já traz de conhecimento consigo. $\mathrm{O}$ professor ao propor o ensino com o uso do lúdico como instrumento metodológico deve partir do pressuposto de que o aluno já traz consigo diversas formas de brincar que devem ser exploradas para o uso desse instrumento metodológico.

A afirmação de Ausubel sobre o saber prévio do aluno nos ajuda a refletir sobre isso, quando cita que:

O ensino deve ocorrer sempre a partir do que o aluno já sabe, organizando o conteúdo de acordo com essa estrutura cognitiva prévia. E, além disso, a predisposição para aprender passa a ser uma condição para aprendizagem (AUSUBEL apud MOREIRA, 1999).

O professor ao se apropriar do lúdico para uso no ensino da matemática, já ultrapassa a barreira da predisposição, pois a metodologia utilizada está em conformidade com sua vontade, aprendendo a ensinar de maneira diferenciada, deixando de lado o ensino mecanizado, sem significado; optando por um ensino, mais contextualizado, significativo e atrativo, que representa uma atividade desafiadora aos alunos para que o processo de aprendizagem seja desencadeado.

Em outras palavras, o professor deve conhecer o recurso que está utilizando, o que permitirá realizar intervenções pedagógicas adequadas no momento da aplicação em sala de aula. $\mathrm{O}$ professor deve estar consciente de que o inesperado e situações imprevisíveis poderão ocorrer com seus alunos, para isso o conhecimento prévio também é fundamental e a partir dessas 
situações inesperadas o professor deve saber intervir para que os alunos possam ter mais autonomia, criando mais responsabilidade e sentimento de socialização.

Não é de um dia para o outro que o professor consegue fazer tais intervenções, principalmente aquele que em nenhum momento de sua formação teve contato com tal instrumento.

Torna-se necessário, nos cursos de formação de professores que ensinam matemática, da criação de um espaço em que os mesmos possam ter contato com o lúdico e condições de aprendizagem acerca da utilização desse instrumento como ferramenta metodológica, para a devida utilização, posteriormente, no ensino da matemática.

Para Antunes:

A utilização dos jogos deve ser somente quando o conteúdo matemático permitir e que seja um instrumento metodológico eficiente na busca do conhecimento por parte dos alunos. (ANTUNES, 1998)

Sem o conhecimento prévio da ferramenta, bem como suas aplicabilidades, o professor fica refém de cometer um erro grave na formação de seus alunos e para não discorrer de tal erro, é fundamental que sua formação lhe propicie tal conhecimento. Faz-se necessária uma reflexão sobre a importância da utilização do lúdico como instrumento metodológico no ensino da matemática e os resultados que proporcionarão um bom aprendizado ao aluno.

O professor precisa ter acesso a esse conhecimento sobre a utilização do lúdico para o ensino de seus alunos. Este conhecimento deve ser despertado desde sua formação inicial, dando-lhe condição de utilização dessa ferramenta. Para que o professor atinja um estágio de maturidade para identificar bloqueios de aprendizagem e quais recursos utilizar para a diminuição desses, deve estar preparado para tal. Um dos espaços em que o professor possa conseguir avanços em seus conhecimentos para a intervenção necessária é o espaço formativo para o exercício de sua função.

Todo ser humano, independente de sua sexualidade, raça, cor, origem, quando brinca, demonstra prazer e alegria em aprender, sem o peso da obrigação do aprender mecanizado. Todos devem ter a oportunidade de lidar com suas energias em busca da satisfação de seus desejos e de resultados satisfatórios para o seu desenvolvimento psíquico.

A curiosidade que os move para participar da brincadeira é, em certo sentido, a mesma que move os cientistas em suas pesquisas; o desejo da descoberta do novo, de algo que antes não era de seu domínio. $\mathrm{O}$ ensino da matemática deve estar relacionado com essa busca incessante do novo, de forma alegre, feliz, descontraída e divertida. 
Todos os aspectos relacionados com o desenvolvimento cognitivo devem ser levados em consideração e que o aspecto afetivo, hoje algo distante de muitas realidades de convívio social, esteja implícito no ato de brincar, uma vez que o elemento mais importante é o envolvimento do indivíduo que brinca, condição essencial para o início da abertura do interesse em adquirir novos conhecimentos.

O que é ensinar matemática, senão o ato de desenvolver o raciocínio lógico, estimular o pensamento independente, a criatividade e a capacidade de resolver problemas. O uso do lúdico como instrumento metodológico para o ensino da matemática necessita de que o professor tenha uma formação para a utilização desse instrumento e uma concepção pedagógica sobre a conquista que o lúdico pode proporcionar. Com isso os avanços para uma aprendizagem mais significativa terão efeito, o que provoca, segundo nossa concepção, uma melhoria substancial na qualidade do ensino da matemática.

\section{Referências}

ALMEIDA, A. Ludicidade como instrumento pedagógico. Disponível em: http://www.cdof.com.br/recrea22.htm. Acesso em: Acesso em: 12/11/2010.

ANTUNES, C. Jogos para Estimulação das Múltiplas inteligências. Petrópolis: Vozes, 1998.

ARANHA, M. L. A. História da Educação. 2a ed.rev. e atual. São Paulo: Moderna,1996.

AUSUBEL, D. P. A aprendizagem significativa: a teoria de David Ausubel. São Paulo: Moraes, 1982.

BATISTA, S. C. F. Softmat: um repositório de softwares para matemática do ensino médio - um instrumento em prol de posturas mais conscientes na seleção de softwares educacionais. Rio de Janeiro. 2004. Dissertação de Mestrado em Ciências da Engenharia. Universidade Estadual do Norte Fluminense (UENF).

Disponível em: <http://www.geogebra.im-uff.mat.br/biblioteca/dissertacao-batista-2004.pdf> Acesso em 10/12/2010.

BRASIL. Ministério da Educação - Secretaria de Educação Fundamental - PCN's: Parâmetros Curriculares Nacionais. Brasília: MEC/SEF, 1997.

CARAÇA, B. J. Conceitos fundamentais da matemática. $3^{\text {a }}$ ed. Lisboa: Gradiva, 2000.

CORBALÁN, F. Juegos matemáticos para secundaria y bachillerato. Madrid: Sintesis, 1994.

D’AMBRÓSIO, B. S. Formação de professores de Matemática para o século XXI: o grande desafio. In: Pró-Posições. Campinas-SP: Cortez Editora/UNICAMP, v. 4, n. 1 (10), 1993. 
FIORENTINI, D. Alguns modos de ver e conceber o ensino de Matemática no Brasil. Revista Zetetiké. Campinas: Unicamp, v. 3, n. 4, p. 1-16, 1995.

GRILO, A. P. S. O lúdico na formação do professor. Disponível em: $<$ http://www.faced.ufba.br/ ludus/trabalhos/2002.1/impludfp.doc >.Acesso em: 12/11/2010

HUBNER, L.; CAPELLI, J.; ELIAS, A. Etnomatemática. Revista Diário do Grande ABC, p. 3, 31 de out. 2003. Disponível em: <http://www.etnomatematica.org/articulos/boletin.pdf $>$. Acesso em 10/12/2010.

HUIZINGA, J. Homo Ludens: o jogo como elemento da cultura. $4^{\text {a }}$ ed. Tradução João Paulo Monteiro. São Paulo: Perspectiva, 2000.

KISHIMOTO, T. M. Brinquedo e Brincadeira - Usos e significações dentro de contextos culturais. In: SANTOS, S. M. P., (org.) Brinquedoteca: O lúdico em diferentes contextos. $3^{\text {a }}$ ed. Petrópolis, Vozes, 1998.

Jogos, brinquedos, brincadeiras e educação. $4^{\text {a }}$ ed. São Paulo: Cortez, 2000.

KISHIMOTO, T. M. (org.). O brincar e suas teorias. São Paulo: Pioneira Thomson Learning, 2002.

LIBÂNEO, J. C. Formação de profissionais da educação: visão crítica e perspectiva de mudança. Disponível em: <http://www.scielo.br/scielo.php?script=sci_arttext\&pid=S010173301999000300013 >. Acesso em: 17/11/2010.

MACEDO, L.; PASSOS, N. C.; PETTY, A. L. S. Os jogos e o lúdico na aprendizagem escolar. Porto Alegre: Artmed, 2005.

MARTINS, M, A. O lúdico como disciplina dos cursos de licenciatura em Matemática Um estudo necessário à formação dos futuros educadores. Disponível em: $<$ http://www.artigonal.com/educacao-artigos/o-ludico-como-disciplina-nos-cursos-de-

licenciatura-em-matematica-um-estudo-necessario-a-formacao-dos-futuros-educadores978278.html>. Acesso em: 17/11/2010.

MOREIRA, M. A. A Teoria da Aprendizagem Significativa de Ausubel. Cap. 10, p. 151-165. In: Teorias da Aprendizagem. São Paulo: Editora Pedagógica e Universitária, EPU, 1999.

A. Aprendizagem Significativa Crítica. Disponível em: http://vicenterisi.googlepages.com/aprend_signif-PostWeingartner.pdf.

MOURA, M. O. A séria busca no jogo: do lúdico na matemática. In: KISHIMOTO, T. M. (org.). Jogo, brinquedo, brincadeira e a educação. São Paulo: Cortez, 1996.

NEGRINE, A. Ludicidade como ciência. In: SANTOS, Santa Marli (Org.). Ludicidade como ciência. Petrópolis: Vozes, 2001.

NÓVOA, A. O professor e a sua formação. Lisboa: Dom Quixote,1991. 
PIAGET, J. A Formação do Símbolo na Criança: Imitação, Jogo e Sonho Imagem a Representação. $2^{\mathrm{a}}$ ed. Rio de Janeiro: Zahar, 1975.

SANTOS, S. M. P. O lúdico na formação do educador. 5ª ed. Rio de Janeiro: Vozes, 1997.

SIMÃO, M. Atividades Lúdicas: Ludicidade e Educação. Referência eletrônica: disponível em: <http://www.nossaescola.com/home/site/lúdico.html>. Acesso em: 10/11/2010.

VYGOTSKYI, L. S. A formação social da mente. $6^{\text {a }}$ ed. São Paulo: Martins Fontes, 1998. 